\title{
Nurse managers' experience with ethical issues in six government hospitals in Malaysia: A cross- sectional study
}

Maizura binti Musa ${ }^{1,2^{*}}$, Md Harun-Or-Rashid ${ }^{1}$ and Junichi Sakamoto ${ }^{1}$

\begin{abstract}
Background: Nurse managers have the burden of experiencing frequent ethical issues related to both their managerial and nursing care duties, according to previous international studies. However, no such study was published in Malaysia. The purpose of this study was to explore nurse managers' experience with ethical issues in six government hospitals in Malaysia including learning about the way they dealt with the issues.

Methods: A cross-sectional study was conducted in August-September, 2010 involving 417 (69.2\%) of total 603 nurse managers in the six Malaysian government hospitals. Data were collected using three-part self-administered questionnaire. Part I was regarding participants' demographics. Part II was about the frequency and areas of management where ethical issues were experienced, and scoring of the importance of 11 pre-identified ethical issues. Part III asked how they dealt with ethical issues in general; ways to deal with the 11 pre-identified ethical issues, and perceived stress level. Data were analyzed using descriptive statistics, cross-tabulations and Pearson's Chi-square.
\end{abstract}

Results: A total of 397 (95.2\%) participants experienced ethical issues and $47.2 \%$ experienced them on weekly to daily basis. Experiencing ethical issues were not associated with areas of practice. Top area of management where ethical issues were encountered was "staff management", but "patient care" related ethical issues were rated as most important. Majority would "discuss with other nurses" in dealing generally with the issues. For pre-identified ethical issues regarding "patient care", "discuss with doctors" was preferred. Only $18.1 \%$ referred issues to "ethics committees" and $53.0 \%$ to the code of ethics.

Conclusions: Nurse managers, regardless of their areas of practice, frequently experienced ethical issues. For dealing with these, team-approach needs to be emphasized. Proper understanding of the code of ethics is needed to provide basis for reasoning.

\section{Background}

The advances in medicine and a more demanding healthcare environment have given rise to various complex ethical issues. Together, they have caused increasing pressure to healthcare professionals, of which nurses are of no exception. A survey by the American Nurses Association (ANA) Center for Ethics and Human Rights at the ANA Convention in 1994 reported that as high as $79 \%$ of their members were confronted with ethical issues on daily to weekly basis [1]. What is meant by "ethical

\footnotetext{
* Correspondence: maizuramusa@yahoo.com

'Young Leaders' Program in Healthcare Administration, Nagoya University

Graduate School of Medicine, Nagoya, Japan

Full list of author information is available at the end of the article
}

issue" is the dilemma on how someone should act morally in a difficult situation, which is "a question of what is the good or right thing to do" [2]. The first so called "code of ethics" was made by Florence Nightingale in 1893 [3]. Since 1953, however, behaviors that are accepted as ethical in nursing practice are those according to the International Council of Nurses' "ICN Code of Ethics for Nurses", which nowadays becomes the basis for nursing practice standards worldwide. It comprises of matters regarding nurses' relationships with "people", "practice", "profession", and "co-workers" [4].

However, this paper is not about overall nursing ethics, but about ethical issues that affect nurse managers. Our interest in studying their experiences was somewhat due
C Biomed Central 
to their unique position. Apart from being front-liners, they also play managerial roles. In other words, nurse managers unlike other nurses are involved not only in patient care, but also have supervision and management responsibilities. They are also members of multi-disciplinary teams and sub-ordinates to doctors [5-7].

Though various ethical issues encountered by nurse managers which warrant attention have been identified, we were unaware of any published study on ethical issues in nursing practice, let alone faced by nurse managers in Malaysia. However, medicine is also advancing here in parallel with rising public expectations to have what they believe as high-quality nursing care. Therefore, it is expected that nurse managers in Malaysia too are experiencing frequent ethical issues. In the absence of previous formal study, the actual burden has not been clearly understood. Moreover, Brosnan J et al. (1997) emphasized that in order to prepare nurse managers for dealing with ethical issues, the first step is to realize what they are, and that such issues are expected to arise in their course of work. The ethical issues may either be rare or day-to-day recurring issues [8].

DeWolf Bosek MS et al. (2006) claimed that understanding nurse managers' role during ethical situation is contingent upon understanding the role and responsibilities associated with the profession [9]. They claimed that nurse managers are the key persons responsible for assisting other nurses evaluate their moral commitments. They also have ethical requirement to lead by example during both easy and desperate times [9]. Marquis BL et al. (2006) also emphasized that nurse managers' responsibilities are beyond that expected from other nurses during an ethical situation [10]. For these reasons, they are expected to be competent in dealing with ethical issues experienced.

We therefore attempted a study on nurse managers in six government hospitals in Malaysia. Its purpose was to explore nurse managers' experience with ethical issues, and to find out how they dealt with the issues. Although we understood that ethical issues are usually dealt with using multi-step approach [11], we were interested in their main action for dealing with the issues.

\section{Methods}

This cross-sectional study was conducted in August and September 2010 involving six Malaysian government hospitals. For convenience, we selected only those major hospitals in Selangor, Putrajaya and the capital city, Kuala Lumpur.

\section{Study population}

All nurse managers of the six hospitals were invited to participate in the study. Two categories were targeted. They were the matrons and sisters occupying managerial and supervisory positions. The matrons are more senior nurses (more than 10 years of experience) and of the highest position. They supervise all nurses including the sisters. The sisters manage the wards and supervise other nurses under them, while they themselves report to the matrons. Apart from this, both are also involved in patient care. We excluded those less than one year of experience as nurse manager.

\section{Instrument}

The study used structured self-administered questionnaire and informed-consent form written in both English and Malaysian language. The questionnaire prepared was guided by the understanding about nursing practice and the code of ethics under Malaysia's nursing practice laws [12]. We used sets of questions with multiple-choice answers provided in order to minimize inconsistencies in responses. Wherever suitable, space was provided to allow participants indicate other answers not listed. A draft version was piloted with five nurse managers. After feedback consideration, final questionnaire comprised of three parts:

Part I: This part is about participants' demographics. These include age-groups, gender, position, years of practice, years of practice as nurse manager, area of practice and hospital name. We also asked whether participants were aware of any committee that discuss ethical issues in the hospitals and their personal participation. Personal identification was not required to ensure anonymity of the participants.

Part II: This part questioned about participants' experiences (whether they have experienced ethical issues since they became nurse managers and if so, how often), areas of management where ethical issues were encountered (five pre-identified areas), and scoring of the importance of 11 pre-identified ethical issues which were important issues faced by nurses and nurse managers based on literature review.[13-15] The issues were: (1) protecting patients' rights; (2) care of patients' quality of life; (3) providing care with possible risks to own health and safety; (4) respecting informed consent by patients to treatment; (5) use of physical or chemical restraints on patients; (6) determining when death occurs; (7) prolonging dying process without appropriate reason; (8) hiding information regarding patients' actual condition from patients or family; (9) working with unethical or incompetent colleague; (10) problems of staffing that limit patients' access to nursing care; and (11) problems of medical resource management that limit patients' access to nursing care. A four-point Likert scale was used for scoring, ranged from 1 (not important) to 4 (very important).

Part III: This part collected responses on how participants generally dealt with ethical issues. Six options were listed, which were: (1) discuss with doctors; (2) discuss 
with other nurses; (3) refer to code of ethics and other guidelines; (4) refer to the hospital's management team; (5) refer to appointed committee that discuss ethical issues; and (6) try solving the issues alone. We also asked how they dealt with the 11 pre-identified ethical issues in part II by using similar six options listed, and inquired their perceived stress level when experiencing these issues by using a four-point Likert scale from 1 (no stress) to 4 (very stressful).

\section{Data collection}

The questionnaires and informed-consent forms were distributed to 603 nurse managers by the hospitals' Heads of Nursing Department (the head matrons), after explanation provided about the study. Completed questionnaires and informed-consent forms were compiled separately by the head matrons before handed in to the researcher. In total, 430 (71.3\%) nurse managers responded but 417 (69.2\%) questionnaires were analyzed. Thirteen questionnaires were excluded from the analyses due to incomplete information.

\section{Statistical analyses}

Statistical analyses were conducted using the Statistical Package for Social Sciences (SPSS) 18 software (by SPSS Inc. 233, South Wacker Drive, $11^{\text {th }}$ Floor, Chicago, IL 60606-6412). Descriptive statistics (frequency and percentage) were used to obtain information about participants' experience, participation in committees that discuss ethical issues, options for dealing generally with ethical issues, stress experience, and their main action (from the six options listed) for dealing with the 11 preidentified ethical issues. For the 11 pre-identified ethical issues, mean importance and mean stress scores were also calculated from the sum of scores given to each issue, divided by total number of participants. Analyses using cross-tabulation and Pearson's Chi-square were done to determine if there were any association between participants' areas of practice with matters of interest, namely participants' experience with ethical issues including frequency of experience, and options chosen for dealing with the issues. Furthermore, we used similar analyses to figure out the relation between participants' participation in committees that discuss ethical issues with the options they chose to deal with the issues. A p value of less than .05 was considered significant.

\section{Approvals}

Approvals were obtained from the head matrons and hospital directors prior to questionnaires distribution. Malaysia's National Institute for Health Behavioral Research approved the overall design and conduct of the study. This study was exempted from the Ministry of
Health of Malaysia's Research Ethics Committee's full Board approval.

\section{Results \\ Participants' demographics}

In total, 52 matrons and 365 sisters participated in the study and majority (39.3\%) were between 51 to 60 years of age. They were predominantly female. The majority have been in practice between 11 to 30 years but most have only been practicing as nurse managers for 5 years or less. Participants were also mostly from the medical care and surgical care areas of practice. Only 72 participants were involved in committees that discuss ethical issues. The details of the participants' demographics are shown in Table 1.

\section{Ethical issues experience}

There were 397 (95.2\%) nurse managers who experienced ethical issues at some point in their practice. Cumulatively, $47.2 \%$ participants experienced ethical issues between weekly to daily. Some participants could not delineate exactly the frequency of experience, whether or not it was yearly or monthly, and chose "occasional" as their answer instead. With regards to areas of management, ethical issues mostly experienced were regarding "staff management", followed by "patient care" and "quality of service delivery" (Table 2).

For the 11 pre-identified ethical issues, the most important issue was "protecting patients' rights". From the mean importance rating order, we also realized that more important ethical issues were in the areas of "patient care". Details are as per Table 3. Of note, we could not find any significant association between participants working in certain areas of practice and their experience with ethical issues.

\section{Dealing with ethical issues}

Altogether, 249 participants felt stressful when dealing with ethical issues and those who didn't was 168. This difference was statistically significant $(\mathrm{p}<.001)$. This means, more than half $(59.7 \%)$ reported they felt stressful. From the 11 pre-identified ethical issues, top most stressful issue was "working with unethical or incompetent colleague". However, ethical issues regarding "patient care" were relatively less stressful (Table 3).

For options in dealing with ethical issues, majority (80.8\%) participants chose "discuss with other nurses" compared to $52.5 \%$ who chose "discuss with doctors" as one of the options. Lesser participants chose "refer to code of ethics and other guidelines"” and "refer to appointed committee that discuss ethical issues" (Table 4). However, for the 11 pre-identified ethical issues many thought that "discuss with doctors" was the main action, especially those related to "patient care" (Table 5). 
Table 1 Participants' demographics

\begin{tabular}{|c|c|c|}
\hline Variables & Frequency & Percentage \\
\hline \multicolumn{3}{|l|}{ Age-group in years $(\mathrm{N}=417)$} \\
\hline 20-30 & 1 & 0.2 \\
\hline $31-40$ & 96 & 23.0 \\
\hline $41-50$ & 154 & 36.9 \\
\hline $51-60$ & 164 & 39.3 \\
\hline$>60$ & 2 & 0.5 \\
\hline \multicolumn{3}{|l|}{$\operatorname{Sex}(N=417)$} \\
\hline Female & 416 & 99.8 \\
\hline Male & 1 & 0.2 \\
\hline \multicolumn{3}{|l|}{ Position as nurse manager $(\mathrm{N}=417)$} \\
\hline Matron & 52 & 12.5 \\
\hline Sister & 365 & 87.5 \\
\hline \multicolumn{3}{|l|}{ Years of practice $(\mathrm{N}=402)$} \\
\hline$\leq 10$ & 10 & 0.7 \\
\hline $11-20$ & 179 & 38.4 \\
\hline $21-30$ & 159 & 36.2 \\
\hline$>30$ & 54 & 20.9 \\
\hline \multicolumn{3}{|l|}{$\begin{array}{l}\text { Years of practice as nurse manager }(\mathrm{N}= \\
413)\end{array}$} \\
\hline$\leq 5$ & 337 & 80.8 \\
\hline $6-10$ & 58 & 13.9 \\
\hline $11-15$ & 13 & 3.1 \\
\hline$>15$ & 5 & 1.2 \\
\hline \multicolumn{3}{|l|}{ Area of practice $(\mathrm{N}=412)$} \\
\hline Multi-clinical disciplines & 40 & 9.6 \\
\hline Medical care ${ }^{a}$ & 113 & 27.1 \\
\hline Surgical care $e^{b}$ & 109 & 26.1 \\
\hline Obstetrics \& Gynecology care & 70 & 16.8 \\
\hline Pediatrics \& Pediatric Surgical care & 35 & 8.4 \\
\hline Anesthesiology \& Critical care & 21 & 5.0 \\
\hline Non-clinical service & 12 & 2.9 \\
\hline Emergency care & 12 & 2.9 \\
\hline \multicolumn{3}{|c|}{ Participation in committee that discuss ethical issues $(N=273)^{c}$} \\
\hline Yes & 72 & 26.4 \\
\hline No & 201 & 73.6 \\
\hline
\end{tabular}

${ }^{a}$ Medical care includes general medicine, cardiology, nephrology, neurology, psychiatry and rehabilitative care.

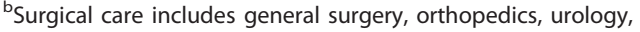
otorhinolaryngology, cardiothoracic and neurosurgery.

${ }^{C}$ From 273 nurse managers who knew there were committees that discuss ethical issues in their hospitals.

From 273 participants who knew their hospitals have committees that discuss ethical issues, 208 (76.2\%) did not choose "refer to appointed committee that discuss ethical issues" as one of the ways to deal with the issues $\left(\mathrm{x}^{2}=13.546\right.$, d.f. $\left.=1, \mathrm{p}<.001\right)$. Moreover, from 72 participants who claimed they were involved in such committees, $66.7 \%$ did not choose "refer to appointed committee that discuss ethical issues" $\left(\mathrm{x}^{2}=4.89\right.$, d.f. $=$ $1, \mathrm{p}=.027)$. We found no association between practicing in certain areas of practice and the options chosen for dealing with ethical issues.
Table 2 Experience with ethical issues

\begin{tabular}{lcr}
\hline Variables & Frequency & Percentage \\
\hline How often ethical issues were & & \\
experienced (N = 417) & 20 & 4.8 \\
Never & 76 & 18.2 \\
Occasional & 49 & 11.8 \\
Yearly & 72 & 17.3 \\
Once a month & 3 & 0.7 \\
Few issues per month & 32 & 7.7 \\
Once a week & 89 & 21.3 \\
Few issues per week & 76 & 18.2 \\
Daily & 281 & 67.4 \\
Areas of management where ethical issues were experienced & \\
Staff management & 271 & 65.0 \\
Patient care & 264 & 63.3 \\
Quality of service delivery & 178 & 42.8 \\
Staff competency assurance & 88 & 21.1 \\
Medical resource management &
\end{tabular}

${ }^{a}$ Multiple answers were accepted. The frequency reflects the total number of nurse managers who chose each answer listed in relation to the total number of nurse managers and similarly, the percentage is the percentage of those who gave answers to the questions in relation to the total number of nurse managers.

\section{Discussion}

This study provides probably the first empirical data and responses to ethical issues by nurse managers in Malaysian hospitals. With this, the burden of ethical issues for nurse managers and the choice of ways for dealing with them could be understood.

\section{Ethical issues experience}

The burden of experience is notably high, where majority nurse managers had previous experiences and almost half of total participants experienced ethical issues between weekly to daily basis. Though most participants experienced ethical issues related to "staff management", the fact that "patient care" came second to this shows that nurses at managerial positions still continue to face frequent ethical issues challenges in "patient care". From the 11 pre-identified ethical issues, it is also evident that four of the five most important ethical issues were related to "patient care", which is in agreement with previous studies [13-15]. However, we did not obtain similar result to those studies that identified problems of medical resources allocation as one of the top ethical issues. Another study has also reported that ethical issue of scanty resources' distribution occurred frequently needing difficult decisions to be made on equity of patient care [16]. A logical answer to our different result is because our participants were working under the instruction of the Heads of Department (usually a medical doctor) of each area of practice. This means nurse managers are able to manage resources, but are not solely 
Table 3 The 11 pre-identified ethical issues: mean importance and mean stress scores

\begin{tabular}{|c|c|c|c|c|c|}
\hline No. & Ethical issues & $\begin{array}{c}\text { Mean } \\
\text { importance } \\
\text { score }^{\mathrm{a}}\end{array}$ & $\begin{array}{l}\text { Mean importance } \\
\text { rating }\end{array}$ & $\begin{array}{l}\text { Mean } \\
\text { stress } \\
\text { score }^{b}\end{array}$ & $\begin{array}{l}\text { Mean stress } \\
\text { rating }\end{array}$ \\
\hline 1. & Protecting patients' rights & 3.82 & 1 & 1.73 & 11 \\
\hline 2. & Care of patients' quality of life & 3.79 & 2 & 1.84 & 10 \\
\hline 3. & Providing care with possible risks to own health and safety & 3.77 & 3 & 2.37 & $5^{c}$ \\
\hline 4. & Respecting informed consent by patients to treatment & 3.57 & 4 & 1.94 & 9 \\
\hline 5. & Use of physical or chemical restraints on patients & 2.78 & 7 & 2.07 & 8 \\
\hline 6. & Determining when death occurs & 2.35 & 9 & 2.19 & 7 \\
\hline 7. & Prolonging dying process without appropriate reason & 2.04 & 11 & 2.37 & $5^{c}$ \\
\hline 8. & $\begin{array}{l}\text { Hiding information regarding patients' actual condition from patients } \\
\text { or family }\end{array}$ & 2.28 & 10 & 2.43 & 4 \\
\hline 9. & Working with unethical or incompetent colleague & 2.44 & 8 & 3.10 & 1 \\
\hline 10. & Problems of staffing that limit patients' access to nursing care & 3.18 & 5 & 2.87 & 2 \\
\hline 11. & $\begin{array}{l}\text { Problems of medical resource management that limit patients' access } \\
\text { to nursing care }\end{array}$ & 3.13 & 6 & 2.77 & 3 \\
\hline
\end{tabular}

a Based on scale of 1 to $4: 1=$ not important, $2=$ slightly important, $3=$ important, $4=$ very important

${ }^{b}$ Based on scale of 1 to $4: 1$ = not stressful, 2 = slightly stressful, $3=$ stressful, $4=$ very stressful

'Same rank because of equal mean

responsible for decisions on resources allocation, hence not much burdened by this issue.

We found no significant association between areas of practice and experience with ethical issues. This is in line with Wood M's study (1999) which concluded that nurse managers acquired competency in ethics through education and years of experience. Their focus on the types of ethical issues and decision-making were not confined within certain areas of practice [17].

\section{Dealing with ethical issues}

The finding of more than half participants reported feeling stressful suggests that dealing with ethical issues is rather burdensome. Among the 11 pre-identified ethical issues, "working with unethical or incompetent colleague" was voted the most stressful. Despite a decline in quality due to overproduction of nurses, majority still possess high competency and professionalism [18]. Therefore, unfamiliar

Table 4 Dealing with ethical issues in general

\begin{tabular}{lcc}
\hline Options in dealing with ethical issues $^{\text {a }}$ & Frequency & Percentage \\
\hline Discuss with doctors & 219 & 52.5 \\
Discuss with other nurses & 337 & 80.8 \\
Refer to code of ethics or other guidelines & 221 & 53.0 \\
Refer to the hospital's management team & 298 & 71.5 \\
Refer to appointed committee that discuss & 78 & 18.7 \\
ethical issues & & \\
Try solving the issues alone & 53 & 12.7 \\
Other methods & 0 & 0.0
\end{tabular}

${ }^{a}$ Multiple answers were accepted. The frequency reflects the total number of nurse managers who chose each answer listed in relation to the total number of nurse managers. Similarly, the percentage is the percentage of those who gave answers to the questions in relation to the total number of nurse managers. situation like dealing with unethical or incompetent colleague would be considerably stressful. Issues regarding "patient care" were relatively less stressful than other areas of management more likely because nurse managers tend to discuss these with doctors and not just among themselves.

Majority participants generally chose "discuss with other nurses" to deal with ethical issues. For sensitive issues regarding "patient care", nurse managers felt "discuss with doctors" was the best option probably as the immediate reliable measure for dealing with the issues. Filipova AA's study (2009) suggested that the way ethical issues are handled reflects the ethics of an organization [19]. Hence, this result implies that the working environment between doctors and nurse managers are still at best situation in the hospitals.

Our study also found out that those who participated in committees that discuss ethical issues ("ethics committees") did not prefer referring the issues to the committee. A logical explanation would be the understanding that "ethics committees" approach depends on the involvement of many parties from different backgrounds [20]. Hence, referring all issues to "ethics committees" would not be feasible due to logistic reasons. If issues are small and require decisions be made quickly, it is understandable that one would utilize a more convenient and immediate measure instead. In addition, de Casterle BD et al. (2002) also pointed out that past discussions leading nowhere or ending in negative consequences could create an atmosphere in which frequent ethical issues are not discussed [21]. Conversely, Parker F (2007) claimed that "ethics committees" meetings could promote professional growth by providing them the opportunity for learning 
Table 5 Participants' main actions in dealing with the 11 pre-identified ethical issues

\begin{tabular}{|c|c|c|c|}
\hline & Ethical issues & Main action & $\begin{array}{l}\text { Percentage of } \\
\text { participants }^{a}\end{array}$ \\
\hline 1. & Protecting patients' rights & Discuss with doctors & 45.0 \\
\hline 2. & Care of patients' quality of life & Discuss with doctors & 44.1 \\
\hline 3. & Providing care with possible risk to own health and safety & Discuss with doctors & 42.4 \\
\hline 4. & Respecting informed consent by patients to treatment & Discuss with doctors & 66.2 \\
\hline 5. & Use of physical or chemical restraints on patients & Discuss with doctors & 65.4 \\
\hline 6. & Determining when death occurs & Discuss with doctors & 79.8 \\
\hline 7. & Prolonging dying process without appropriate reason & Discuss with doctors & 79.3 \\
\hline 8. & $\begin{array}{l}\text { Hiding information regarding patients' actual condition from patients or } \\
\text { family }\end{array}$ & Discuss with doctors & 67.7 \\
\hline 9. & Working with unethical or incompetent colleague & Discuss with other nurses & 34.3 \\
\hline 10. & Problems of staffing that limit patients' access to nursing care & $\begin{array}{l}\text { Refer to the hospital's management } \\
\text { team }\end{array}$ & 40.9 \\
\hline 11. & $\begin{array}{c}\text { Problems of medical resource management that limit patients' access to } \\
\text { nursing care }\end{array}$ & $\begin{array}{c}\text { Refer to the hospital's management } \\
\text { team }\end{array}$ & 40.3 \\
\hline
\end{tabular}

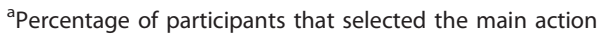

how to address ethical issues from multi-disciplinary experts' different perspectives [22]. Hence, nurse managers engaged in "ethics committees" could have learnt from previous decisions on how to address some ethical issues.

To date, the Malaysia Nursing Board has come out not only with its code of ethics, but with 25 other guidelines to ensure nursing practice is carried out according to the accepted norms. Although this is so, only about half of total nurse managers would refer to the code of ethics for dealing with ethical issues. Nevertheless, similar finding was also obtained in other studies. When deciding on how to handle ethical issues, nurse managers usually rely on three things: their personal skills, the management team or other nurses, or the code of ethics. In most cases, the latter was the least referred. Its usefulness in decision making had even been criticized. One criticism was that although code of ethics compliance is crucial to prevent unethical or illegal practices, it inadequately guides one's thoughts in formulating a viewpoint or judgement in dealing with ethical issues $[23,24]$.

The fact that we could not find any association between areas of practice and choice of dealing with ethical issues points out to the suggestion that any organizational improvement going to be made need not be targeted to certain areas of practice.

A couple of study limitations related to the use of selfadministered questionnaire are worthy of attention. Firstly, we used a list of pre-identified ethical issues originally intended to avoid inconsistencies in the answers. Hence, we did not ask their experience with issues such as ethics of organ transplant and surrogate decision-making as in a previous study [14]. However, some of our hospitals have no organ transplant service, so participants were unable to answer it anyway; moreover, surrogacy is prohibited in the country. In addition, not using openended questions or exhaustive list in this study lead to limited options that precluded new input and provision of exact descriptions from the participants on the types of ethical issues they experienced. As a result, we could not identify whether or not there were any ethical issues that may be unique to nurse managers in these hospitals especially those that may be related to their cultural and social backgrounds. Secondly, our participants were not randomly selected. While questionnaires were distributed to all nurse managers with the expectation of full participation, only two-third responded. Therefore, possibility exist that non-respondent nurse managers might be representative of specific group of population with unique experience and understanding of ethical issues. However, our method obtained better response compared to $15 \%-52 \%$ in previous studies which utilized traditional mailing system as communication means [13-15], where responses were largely dependent upon participants' willingness to return pre-stamped envelopes back to the sender. A third limitation is that participants' experiences were based on their recall of past encounters of ethical issues. We solely relied on their own knowledge about ethical issues to correctly recall they have previously experienced them.

\section{Conclusions}

The frequent experience with ethical issues suggests that awareness is still needed for nurses who already reached nurse manager positions. Ethical issues require reasoned and rational approach to be dealt with appropriately. Nurse managers regard support from other nurses as essential but discussion with co-workers such as doctors is still important especially when dealing with "patient care" ethical issues. This points out to the consideration 
that team-approach is necessary, ideally the team which can serve as a quick and reliable resource for dealing with the issues, and this is best combined with proper understanding of the code of ethics as basis for reasoning. We hope this information can provide basis for enhancing support for nurse managers' workforce and professional developments, and to improve organizational approach in dealing with ethical issues. We recommend further studies, including qualitative studies to be conducted in hospitals nationwide, in other types of healthcare institutions, or among nurses of different levels in order to obtain wider perspectives.

\section{Acknowledgements}

The authors would like to thank the Heads of Nursing Department and the Directors of Hospital Kuala Lumpur, Hospital Sungai Buloh, Hospital Selayang, Hospital Tuanku Ampuan Rahimah Klang, Hospital Serdang, and Hospital Putrajaya for their approval as well as the assistance given during questionnaires distribution and collection. Special thanks to Matron Zainooriah binti Dato' Hj Zakaria, the current secretary of the Malaysia Nursing Board for intellectual input given for the paper. The authors would also like to thank the Director General of Health of Malaysia for his permission to publish this paper. This study was supported in part by "Epidemiological and Clinical Research Information Network (ECRIN)", a nonprofit organization.

\section{Author details}

'Young Leaders' Program in Healthcare Administration, Nagoya University Graduate School of Medicine, Nagoya, Japan. ${ }^{2}$ Medical Practice Division, Ministry of Health, Putrajaya, Malaysia.

\section{Authors' contributions}

MbM conducted the research, did the statistical analyses and wrote the initial manuscript, MHOR and JS reviewed the statistical analyses and edited the manuscript. All the authors have read and approved the manuscript.

\section{Competing interests}

The authors declare that they have no competing interests.

Received: 9 June 2011 Accepted: 16 November 2011

Published: 16 November 2011

\section{References}

1. Scanlon C: Survey yields significant results. Communique 1994, 4:1-3.

2. Redman BK, Fry ST: Nurses' ethical conflicts: what is really known about them? Nurs Ethics 2000, 7:360-366.

3. Bostridge M: Florence Nightingale: The Making of an Icon Illustrated edn: Indiana University Press; 2008.

4. International Council of Nurses: The ICN Code of Ethics for Nurses Geneva, Switzerland: Imprimerie Fornara; 2005

5. Hisar F, Karadag A: Determining the professional behaviour of nurse executives. Int I Nurs Pract 2010, 16:335-341.

6. Wilson-Barnett J: Ethical dilemmas in nursing. J Med Ethics 1986, 12:123-126, 135.

7. Mitchell JR: Is nursing any business of doctors? A simple guide to the "nursing process". In Br Med J Edited by: Clin Res 1984, 288:216-219.

8. Brosnan J, Roper JM: The reality of political ethical conflicts. Nurse manager dilemmas. J Nurs Adm 1997, 27:42-46.

9. DeWolf Bosek MS, Stammer K: Ethical commitments during desperate times. JONAS Healthc Law Ethics Regul 2006, 8:123-128.

10. Marquis BL, Huston CJ: Leadership Roles and Management Functions in Nursing: Theory and Application. 6 edition. Philadelphia PA 19106: Lippincott Williams \& Wilkins; 2008

11. Toren $\mathrm{O}$, Wagner $\mathrm{N}$ : Applying an ethical decision-making tool to a nurse management dilemma. Nurs Ethics 2010, 17:393-402.
12. Nurses Act 1950 (Revised 1969) \& Nurses Registration Regulations. 1985 [http://www.agc.gov.my/Akta/Vol.\%201/Act\%2014.pdf].

13. Cooper RW, Frank GL, Hansen MM, Gouty CA: Key ethical issues encountered in healthcare organizations: the perceptions of staff nurses and nurse leaders. J Nurs Adm 2004, 34:149-156.

14. Ulrich CM, Taylor C, Soeken K, O'Donnell P, Farrar A, Danis M, Grady C: Everyday ethics: ethical issues and stress in nursing practice. J Adv Nurs 2010, 66:2510-2519.

15. Aitamaa E, Leino-Kilpi H, Puukka P, Suhonen R: Ethical problems in nursing management: the role of codes of ethics. Nurs Ethics 2010, 17:469-482.

16. Williams A: Thinking about equity in health care. J Nurs Manag 2005, 13:397-402.

17. Woods M: A nursing ethic: the moral voice of experienced nurses. Nurs Ethics 1999, 6:423-433.

18. Nemie JKP: Challenges for the nursing profession in Malaysia: Evolving legal and ethical standards. Journal of Nursing Law 2009, 13:54-62.

19. Filipova AA: Licensed nurses' perceptions of ethical climates in skilled nursing facilities. Nurs Ethics 2009, 16:574-588

20. Keffer MJ: Why nursing ethics committees? HEC Forum 1997, 9:50-54

21. Dierckx de Casterle B, Meulenbergs T, van de Vijver L, Tanghe A, Gastmans $C$ : Ethics meetings in support of good nursing care: some practice-based thoughts. Nurs Ethics 2002, 9:612-622.

22. Parker FM: Ethics: The power of one. OJIN: Online Journal of Issues in Nursing 2007, 13.

23. Borawski DB: Resources used by nurse administrators in ethical decisionmaking. J Nurs Adm 1994, 24:17-22.

24. Pattison S: Are nursing codes of practice ethical? Nurs Ethics 2001, 8:5-18

\section{Pre-publication history}

The pre-publication history for this paper can be accessed here: http://www.biomedcentral.com/1472-6939/12/23/prepub

doi:10.1186/1472-6939-12-23

Cite this article as: Musa et al:: Nurse managers' experience with ethical issues in six government hospitals in Malaysia: A cross-sectional study. BMC Medical Ethics 2011 12:23.

\section{Submit your next manuscript to BioMed Central and take full advantage of:}

- Convenient online submission

- Thorough peer review

- No space constraints or color figure charges

- Immediate publication on acceptance

- Inclusion in PubMed, CAS, Scopus and Google Scholar

- Research which is freely available for redistribution 